\title{
Ameliorating the Aphrodisiac Effect of Stephania wightii Arn. (Dunn) on Animal Model
}

\author{
Article by U. Danya \\ Ph.D., Nirmala College for Women, India \\ E mail: danya.bio@gmail.com
}

\begin{abstract}
Stephania wightii is an endemic medicinal plant traditionally used in India for various ailments. This study was set out to evaluate the aphrodisiac properties of methanolic aerial parts and tuber extracts of Stephania wightii using animal models. The methanolic tuber extract of S. wightii at the dose of $100 \mathrm{mg} / \mathrm{kg}$ body weight showed significant aphrodisiac activity on male wistar albino rats as evidenced by an increased the levels of reproductive hormones serum testosterone, Serum Luteinizing hormone and Serum Follicle-stimulating hormone. The efficiency was higher in the extract treated animals compared to the standard drug treated animal.
\end{abstract}

Keywords: Aphrodisiac, Stephania wightii, testosterone, Luteinizing hormone, Folliclestimulating hormone and animal model

\section{Introduction}

An aphrodisiac is defined as an agent (food or drug) that arouses sexual desire. Some medicinal plants are extensively used as aphrodisiacs to relieve sexual dysfunction, or as fertility- enhancing agents. They provide a boost of nutritional value thereby improving sexual performance and libido (Yakubu et al., 2005).

The family Menispermaceae consists of 70 genera and approximately 400 species. The species of Stephania have been proven to be a rich source of phytoconstituents like alkaloids, flavanoids, terpenoids, phenols, saponins and steroids. These plants also have been traditionally used for the treatment of asthma, tuberculosis, dysentery, hyperglycemia, cancer, fever, intestinal complaints, aphrodisiac, sleep disturbances and inflammation (Chopra et al., 1958 and Gaur, 1999). The use of allopathic medicines has large number of side effects. These include irregularities of the rhythm of the heart, suicidal tendencies, mental disorders and tremors. Therefore it is necessary to look for an urgent solution to manage this problem.

\section{Materials and methods}

\section{Collection of plant material}

Aerial and tuber parts of $S$. wightii (except floral parts) was collected during the month of January 2011, from Wyanad district, Western Ghats of Kerala. The plant was identified and authenticated by a plant taxonomist.

\section{Crude drug preparation}

Freshly collected sample of $S$. wightii (aerial parts and tuber) from wild and were washed separately for 2-3 times with tap water followed by distilled water. The samples were dried under shade. All the dried parts were pulverized by mechanical grinder to get the powder through 100 mess sieve and then stored in an air tight container. Required quantity of powder was weighed and transferred to conical flask. The powder was fully immersed and extracted with petroleum ether first and defatted. The defatted samples were treated with methanol and it was placed in the mechanical shaker. This process was repeated for 1 week and then the extract was filtered through whatman paper. The filtrate was collected and evaporated to dryness. The concentrated residue was stored in the refrigerator for $4^{\circ} \mathrm{C}$ and it was used for the biological studies. 
South American Journal of Academic Research

Special Edition May 2016

\section{Aphrodisiac activity}

\section{Experimental animals}

Male and Female Wistar albino rats were obtained from the Animal house, Agricultural University, Trissur, Kerala. Feed (standard pellet diet) and water were supplied ad libitum. All the animals were housed and maintained at a temperature of $20-24^{\circ} \mathrm{C}$, relative humidity of 50-70\%, and a $12 \mathrm{~h}$ light/dark cycle.

The experimental protocol has been approved by the Institution Animal Ethics committee and by the Regulatory body of the government (659/02/a/CPCSEA).

\section{Preparation of male and female rats}

The sexually active male rats were selected for the testing aphrodisiac activity of the extracts. Sildenafil citrate $(0.5 \mathrm{mg} / \mathrm{kg})$ body weight has given to the male rats prior to experimentation. The female rats were brought in oestrous phase by treating them with Estradiol valerate $(10 \mu \mathrm{g} / \mathrm{kg}$ body wt.) and hydroxy progesterone $(1.5 \mathrm{mg} / \mathrm{kg}$ b.wt.) for 5 hours prior to experimentation respectively, to make them for sexually acceptable and were selected for the study.

Follicle Stimulating Hormone (FSH), Lutinizing Hormone (LH) and Testosterone (T) levels were estimated by the method of Tietz (1995).

\section{Experimental design}

Group I: Rats given normal saline given (by using an intragastric catheter tube (IGC).

Group II: Rats given methanolic extract of aerial parts of S. wightii drug at the dose of 100 $\mathrm{mg} / \mathrm{Kg}$ body weight, orally by IGC.

Group III: Rats given methanolic extract of tuber of $S$. wightii drug at the dose of $100 \mathrm{mg} /$ Kg body weight orally by IGC.

Group IV: Rats given standard drug Sildenafil citrate (5 mg/kg body weight) $1 \mathrm{~h}$ prior to the commencement of the experiment.

\section{Result and discussion}

\section{Reproductive hormone profile}

The administration of methanolic extracts of aerial and tuber parts of S. wightii resulted in a significant increase in serum testosterone, Serum Luteinizing hormone and Serum Folliclestimulating hormone concentrations throughout the period of administration $(P<0.05)$ and the elevation of these hormones levels were recorded in tuber extract treated rats at the dose of $100 \mathrm{mg} / \mathrm{kg}$ b.wt. The moderate activity observed in the aerial parts extract treated groups. All the results compared with control groups (Table 1).

Table 1: Effect of methanolic extract of aerial parts and tuber of Stephania wightii on sex hormones levels in male albino rats

\begin{tabular}{|l|c|c|c|}
\hline \multirow{2}{*}{$\begin{array}{l}\text { Treatment } \\
\text { Groups }\end{array}$} & \multicolumn{3}{|c|}{ Parameters } \\
\cline { 2 - 4 } & Testosterone $(\mathbf{n g} / \mathbf{m l})$ & $\mathbf{L H} / \mathbf{I C S H}(\boldsymbol{\mu I \mathbf { I }} / \mathbf{m l})$ & FSH $(\boldsymbol{\mu I \mathbf { I }} / \mathbf{m l})$ \\
\hline Group I & $2.13 \pm 0.62$ & $1.54 \pm 0.34$ & $0.89 \pm 0.04$ \\
\hline Group II & $2.31 \pm 0.73$ & $0.91 \pm 0.64$ & $3.41 \pm 0.41^{* *}$ \\
\hline Group III & $4.01 \pm 0.29^{* *}$ & $1.06 \pm 0.91^{*}$ & $2.64 \pm 0.55^{* *}$ \\
\hline Group IV & $4.33 \pm 0.74^{*}$ & $1.33 \pm 0.51$ & $1.87 \pm 0.84$ \\
\hline
\end{tabular}

Each Value is SEM of 5 animals * $\mathrm{P}<0.05$. Control Vs Treat; NS-not singnificant. 
Testosterone supplementation has previously shown to improve sexual function and libido (Aversa and Fabbri, 2001), in addition to the intensity of orgasm and ejaculation which is likely to improve (Morales, 1996). It also helps in maintaining body shape, and increasing muscle mass and strength. Therefore, the increase in testosterone will enhance androgendependent parameters like mating behaviour, blood count, bone density and maintenance of spermatogenesis (Pardridge, 1986). Luteinizing hormones (LH) and Follicle Stimulating Hormone (FSH) produced by anterior pituitary lobe are necessary for maintaining testosterone levels such that as LH and FSH increases so do the testosterone. Therefore, a medicinal plant acclaimed to have aphrodisiac potential apart from being able to increase the concentration of bioavailable/free testosterone should cause increase in the concentrations of serum LH and FSH. An increase in the concentrations of LH and FSH should normally increase the testosterone concentration. Therefore, an increase in testicular and serum free testosterone concentration confirmed aphrodisiac potential inherent of $S$. wightii.

\section{Conclusion}

Stephania wightii is an endemic medicinal plant used in the treatment of various ailments in the history of traditional medicine. It has been reported that they contain major Phytoconstituents like alkaloids, flavanoids, terpenoids, phenols, saponins and steroids. These phytoconstituents may be responsible for the presently observed pharmacological activity. Apart from these, isolation, characterization of the active constituents and discovery of novel drugs of $S$. wightii will be suggested for further study.

\section{References}

[1.] Yakubu M.T., A.M. Akanji and A.T. Oladiji, 2005. Aphrodisiac potentials of the aqueous extract of Fadogia agrestis (Schweinf. Ex Hiern) stem in male albino rats. Asian J. Androl., 7: 399-404.

[2.] Gaur R.D., 1999. Flora of district Garhwal North West Himalaya (with ethnobotanical notes) Ist ed. Transmedia Srinagar Garhwal, India, pp: 76-77.

[3.] Chopra R.N., I.C. Chopra, K.L. Handa and L.D. Kapur, 1958. Chopra’s Indigenous Drugs of India, 2nd ed. Char UN and Sons, Ltd., Calcutta, India, pp: 412.

[4.] Tietz N.W., 1995. Clinical guide to laboratory tests, 3rd edition, (Ed) W. B. Saunders, Philadelphia, pp: 578-580.

[5.] Aversa A and A. Fabbri, 2001. New oral agents for erectile dysfunction: what is changing in our practice? Asian J. Androl., 3: 175-179.

[6.] Morales A., 1996. Androgen supplementation in practice: the treatment of erectile dysfunction associated with hypotestosteronemia. In: Oddens BJ, Vermeulen A, (Eds). Androgens and aging male. London: Parthenon Publishing Group, pp: 233-45.

[7.] Pardridge W. M., 1986. Serum bioavailability of sex steroid hormones. Clin Endocrinol Metab, 15: 259-278. 